\title{
Görsel Geri Bildirimin Postür Üzerine Etkisinin Araştırılması \\ Investigation of The Effects of Visual Feedback on Posture
}

\section{Leyla KAYA ${ }^{1}$, Çiğdem ÖKsÜZ ${ }^{2}$}

${ }^{1}$ Erg., Hacettepe Üniversitesi Sağlık Bilimleri Fakültesi Ergoterapi Bölümü, Ankara

${ }^{2}$ Doç. Dr., Hacettepe Üniversitesi Sağlık Bilimleri Fakültesi Ergoterapi Bölümü, Ankara

Amaç: Çalışmanın amacı, sanal ortamda sağlanan görsel geri bildirimin, bireylerin postürlerine olan etkisinin araştırılmasıdır. Gereç ve Yöntem: Bireylerden bilgisayar ekranında önce sadece yazı programı açık iken, daha sonra ekranın yarı kısmında Word dosyası yarı kısmında ise ön kameradan sağlanan görüntü ekranda görünür durumda iken belirlenen metni yazmaları istendi. Kişilerin postürleri, bu sırada yan kamera aracılığıyla kaydedildi. Hızlı Üst Ekstremite Değerlendirmesi (Rapid Upper Limb Assesment-RULA) ile postüral değişimler incelendi. Sonuçlar: Bireylerin görsel geri bildirime baktıkları her anda postürlerini değiştirdikleri sonucuna varılmıştır. Tartışma: Görsel geri bildirim ile postür arasında bir ilişki olduğu ve hazırlanan sanal ortamda görsel geri bildirimin postüre etki ettiği sonucuna varılmıştır.

Anahtar Kelimeler: Geri bildirim; Postür; Ergonomi

\section{A B S TRACT}

Purpose: The aim of the study was to investigate the effect of visual feedback provided in a virtual environment to individual's posture. Material and Methods: 10 people were asked to write a text firstly while writing program (Word) appeared on the screen, secondly while in one half of the screen writing program in other half of the screen the image supplied from the front camera appeared on the screen. Meanwhile, posture of people were recorded through the lateral camera. Rapid Upper Limb Assessment (Rapid Upper Limb-Assesment RULA) were used to examine postural changes. Results: It concluded that individuals change their posture every time they look at the visual feedback. Conclusion: it was concluded that there is a relationship between posture and visual feedback and visual feedback prepared in a virtual environment has effect on posture,

Key Words: Visual feedback; Posture; Ergonomics 
Dostür, vücudumuzun tüm kısımlarının en uygun pozisyonda yerleştirilmiş halidir.Bu pozisyon, doğru veya yanlış kazanılan alışkanlıklarımızdan oluşur. İyi postür doğru kazanılmış alışkanlık iken kötü postür yanlış kazanılmış bir alışkanlık olarak ifade edilebilmektedir (Açık, Kayıhan, Aran, 2014). Günlük hayatta postürümüz birçok faktörden etkilenmektedir. Bu faktörlerden birisi de görsel geribildirimdir (Kelly, Riecke, Loomis, Beall, 2008).

Görsel geri bildirim; dış ortamdan bireye ulaşan görsel bildirimlerin, bireyin yanıt olarak dış ortama verdiği duyusal geri bildirim olarak tanımlanabilmektedir(Sato ve ark.,2010).

Görsel bildirimin sağlanabildiği yöntemlerden birisi olan ayna terapisi, ilk olarak 1990'larda Rogers ve Ramachandran tarafından amputelerde fantom ağrısı için tasarlanmıştır. Fantom ağrısının tedavisinde ilerlemelerin kaydedilmesiyle ayna terapisi, inme, kompleks bölgesel ağrı sendromu, kırıklar gibi çeşitli hastalıkların tedavisinde kullanılmaya başlanmıştır (Altschuler, Hu, 2008; Selles, Schreuders, Stam, 2008; Yavuzer ve ark., 2008). Ayna aracılığıyla sağlanan görsel geri bildirim ile doğru postürün anlaşıması ve yanlış kazanılan postürün düzeltilmesi amaçlanmaktadır (McCabe, 2011). Ayna aracılığıyla alınan geri bildirim gibi,dış ortamdan alınan görsel geribildirim ile bireyin oluşturduğu postüral yanıtlar arasında bir ilişki olduğu belirtilen bir çalışma yapılmıştır. Yapılan çalışmada görsel geribildirimin postür üzerindeki etkilerini ortaya koyabilmek amacıyla simule görsel sahnelerin olduğu sanal ortamlar hazırlanmıştır. Hazırlanan sanal ortamlarda postüral kontrolü etkileyebilen herhangi bir sistemin, gerçek ortamda da uygulanması halinde benzer etkilerin ortaya çıkacağı gösterilmiştir. Aynı zamanda postürün düzeltilebilmesi için sanal ortamların kullanılabileceği sonucu ortaya çıkmıştır (Kelly ve ark., 2008).

Postürün düzeltilmesi için oluşturulan diğer bir sistem olan, kendini izleme yöntemi (self-monitoring)ile kişinin kendisini izleyerek bir gözlemci gibi postürünün farkına varması ve postürün olumlu değişimleri amaçlanmıştır. Bu yöntemin kullanıldığı birçok çalışmaya rastlanmaktadır (Sigurdsson, Austin, 2008). Örneğin McCann ve Sulzer-Azaroff, güvenli oturma postürünü oluşturmak amacıyla kendini izleme (self- monitoring) yöntemini kullandığı çalışmalarının sonucunda,doğru postür ile ilgili eğitimlerin verilmesi ile birlikte kendini izleme yöntemini kullanarak, postürde düzelmeler kaydedildiği belirtilmiştir (McCann, Sulzer-Azaroff, 1996). Görsel geri bildirimin kişiye hareketi sırasında, anında verilmesi demek olan gerçek zamanlı görsel geri bildirimin kullanıldığı bir çalışmada, kişiler bilgisayar başında yazı yazma sırasında postüral hareketlerini izlemişlerdir. Bu sırada bireylerin postürlerinde olumlu gelişmeler kaydedildiği belirtilmiştir (Sigurdsson, Austin, 2008).

Bu çalışmanın amacı; bireylerin, kendini izleme yöntemini bir aktivite sırasında kullandıkları zaman, görsel olarak geri bildirim alıp almadıkları ve alınabilecek görsel geri bildirim ile postürlerinde oluşabilecek değişimleri araştırmaktır.

\section{GEREÇ VE YÖNTEM}

Çalışmaya yaş aralığı 18-22 yıl olan 7 kadın ve 6 erkek $(n=13)$ üniversite öğrencisi gönüllülük esası ile dahil edilmiştir. Sağlanan gerçek zamanlı görsel geri bildirimin etkisinin daha iyi anlaşılabilmesi için hem doğru postür hakkında daha önce eğitim almayan hem de postürünü olumsuz etkileyebilecek bir hastalığı ( ankilozan spondilit, skolyoz vb) bulunmayan sağlıklı bireyler çalışmaya dahil edilmiştir. Bireylerden, çalışmaya dahil olma, video ve fotoğraf çekimleri, çalışma için bunları kullanabilme adına, bilgilendirilmiş bir onam formu alınmıştır. Çalışmanın yapılacağı gün, bireylere uyku, yorgunluk veya ağrı şikayetinin varlığı sorulmuş ve kendilerini iyi hissettikleri zamana göre çalışma saati planlanmıştır. Katılımcıların klavyeye olan hakimiyetlerinin anlaşılması için 1 dakikada kaç kelime yazdıklarına bakılmış ve dakikada ortalama olarak 20-25 kelime yazabilen bireylerden oluşan katılımcı grubu dahil edilmiştir. Çalışma 2015 yılının Şubat ayında çalışmaya uygun olarak hazırlanmış bir ofis ortamında gerçekleştirilmiştir.

Her bir bireyden standart bir masa üzerine yerleştirilmiş standart masaüstü bir bilgisayarda önceden belirlenmiş, katılımcıların kolaylıkla yazabileceği, yaklaşık olarak 350 kelimeden oluşan, basit, anlaşılır bir metini yazmaları istenmiştir. Bireylerin değerlendirme sırasında kullandıkları sandalye uygun kolçaksız ve ayarlanabilir bir sandalye olarak seçilmiştir. Bireylerin değerlendir- 
meye başlamadan önce sandalye ve masayı kendi postürlerine göre ayarlamalarına izin verilmiş fakat bu yönde bir uyarı yapılmamıştır. Değerlendirmeler ofis ortamında uygun ışıklandırma içerisinde yapılmıştır. Webcam kişinin boyuna göre kendisini görebilecek şekilde pozisyonlanmıştır.

Bireylerden bilgisayar ekranında önce sadece yazı programı (Word) açık iken, daha sonra ekranın yarı kısmında yazı programı (Word) yarı kısmında ise ön kameradan sağlanan görüntü ekranda görünür durumda iken belirlenen metni yazmaları istenmiştir. Bireyler metni yazma esnasında ön kameradan ve kişinin lateraline yerleştirilen kameradan videoya alınmıştır. Ekranda sadece Word dosyası açık iken yapılan çekim 1 . çekim, hem Word dosyası hem de ön kameradan sağlanan görüntü ekranda iken yapılan çekim ise 2. çekim olarak adlandırımıştır.

Kişinin ekrandaki görüntüsüne bakıp bakmadığını anlayabilmek için ise Webcam Max programı kullanılmıştır. Bu program ile hem ön kameradan sağlanan görüntünün ekrana verilmesi hem de bu süre zarfında videoya alınması sağlanmıştır.

Görsel geribildirimin postüral etkisini değerlendirmek için kişiye 1-1.5 m uzaklıkta laterale yerleştirilmiş kameradan alınan video ile postüral değişiklikler hesaplanmıştır. Laterale yerleştirilen kamera ile ise ekrandaki görüntüsüne baktığı an ve baktıktan 2 saniye sonraki postürünün karşıIaştırıması sağlanmıştır. Bunun dışında lateral kamera ile 1. ve 2. çekimlerdeki en kötü postürleri karşılaştırılmıştır.

Postürün değerlendirilmesi için videolarda anlık durdurup fotoğraflayan Ekran Alıntısı AraCı kullanılış̧tır. Alınan görüntüler Ergo Fellow programına aktarımıştır. Ergo Fellow programı mesleki riskleri azaltmak ve verimliliği artırmak amacıyla, iş yeri koşullarının değerlendirilmesi ve iyileştirilmesi için 17 ergonomik araca sahip bir bilgisayar yazııımıdır. Yazılım ergonomistler gibi iş sağlığı ve güvenliği alanındaki tüm profesyoneller için kullanışlıdır. Her bir fotoğraf Ergo Fellow programında 'Image Analysis' kısmında' boyun lateral fleksiyonu, gövde fleksiyonu, omuz fleksiyonu, dirsek fleksiyonu' açıları bulunmuştur. Açılar belirlendikten sonra yine Ergo Fellow programında hızlı üst ekstremite değerlendirmesi (Rapid Upper Limb Assesment-RULA) değerlendirmesine alınmıştır (Deros, Ali, Mohamad, Daruis, 2016).
RULA herhangi bir iş sırasında gerekli hareketleri dikkate alarak üst ekstremite problemlerini açığa çıkarmak amacıyla geliştirilmiş, çalışma duruşlarını değerlendiren bir yöntemdir (Dockrell ve ark., 2012). Az ekipman ile kolaylıkla yapılan ve çevre değişikliklerine duyarlı bir sistemdir (Esen, Fığlalı, 2013).Ergonomik değerlendirme aracı olan RULA iş görevlerinde biyomekanik ve postüral yük gereksinimlerini değerlendirmektedir. Vücut postürü, kuvvet ve tekrarı değerlendirerek belli bir risk faktörü derecesi açığa çıkmış olur. 7 puan üzerinden risk derecesi hesaplanır. 1-2 puan risk yok, 3-4 puan düşük risk, 5-6 orta dereceli risk, 7 puan yüksek dereceli riski ifade etmektedir (Levanon, Lerman, Gefen, Ratzon, 2014). RULA değerlendirmesi kullanılarak, kişilerin postürlerinin risk derecesi ve değişimi hesaplanmıştır.

\section{SONUÇLAR}

Katılımcıların tümü üniversite öğrencisi olup, yaş ortalamaları $21.1 \pm 1.66$ yıl olan 6 erkek 7 kadın olmak üzere 13 kişi katılmıştır. Bu bireylerden 2 erkek ve 1 kadın, verilerin kalitesi yetersiz olduğu için çalışmadan çıkarılmıştır. 4 erkek 6 kadın olmak üzere 10 kişi ile çalışma tamamlanmıştır. ÇaIışmaya katılan 10 kişiden 9'u farklı zaman dilimlerinde ekrandaki görüntülerine bakmış, yalnızca 1 kişi ön kameradan yansıtılan görüntüsüne hiç bakmamıştır. Bakmayan bir kişi için 1. çekimde (ekranda ön kameradan yansıyan görüntü olmadan) en kötü postürüne bakıldığında; boyun fleksiyonu 39, gövde fleksiyonu 27, omuz fleksiyonu 19, dirsek fleksiyonu 17 derece ve RULA değerinde risk derecesi 4 (düşük dereceli risk) olarak bulunmuştur. 2. çekimde (ekranda kameraya yansıyan görünü var iken) ise en kötü postürüne bakıldığında; boyun fleksiyonu 38, gövde fleksiyonu 31, omuz fleksiyonu 9, dirsek fleksiyonu 105 derece ve RULA değerinde risk derecesi 4 ( düşük dereceli risk) olarak bulunmuştur. I. ve II. çekim arasında en kötü postürlerinde risk dereceleri bakımından herhangi bir değişim olmadığı sonucuna varılmıştır.

Çekimler sırasında, kişilerin sergiledikleri en kötü postürleri anlık olarak fotoğraflanıp dereceleri Tablo 1 ve Tablo 2'de gösterilmiştir. Bilgisayar ekranında kişinin ön kameradan yansıyan görüntüsü olmadan yapılmış I. çekimin sonucu Tablo 1'de ve ön kamera aracılığıyla ekranda 
Tablo 1. Katılımcıların 1. çekim sırasındaki en kötü postür ve RULA değerleri (Değerler derece cinsinden verilmiştir.)

\begin{tabular}{cccccc}
\hline KatılımcI & $\begin{array}{c}\text { Boyun } \\
\text { fleksiyonu }\end{array}$ & $\begin{array}{c}\text { Gövde } \\
\text { fleksiyonu }\end{array}$ & $\begin{array}{c}\text { Omuz } \\
\text { fleksiyonu }\end{array}$ & $\begin{array}{c}\text { Dirsek } \\
\text { fleksiyonu }\end{array}$ & RULA \\
\hline 1 & 40 & 45 & 33 & 126 & 6 \\
\hline 2 & 38 & 26 & 33 & 88 & 5 \\
\hline 3 & 42 & 37 & 33 & 53 & 6 \\
\hline 4 & 57 & 14 & 5 & 86 & 6 \\
\hline 5 & 55 & 32 & 22 & 93 & 5 \\
\hline 6 & 51 & 42 & 19 & 90 & 5 \\
\hline 7 & 38 & 31 & 30 & 61 & 6 \\
\hline 8 & 43 & 29 & 6 & 122 & 4 \\
\hline 9 & 68 & 37 & 5 & 116 & 4 \\
\hline
\end{tabular}

Tablo 2. Katılımcıların 2. çekim sırasındaki en kötü postür ve RULA değerleri (Değerler derece cinsinden verilmiştir)

\begin{tabular}{cccccc}
\hline Katılımcı & $\begin{array}{c}\text { Boyun } \\
\text { fleksiyonu }\end{array}$ & $\begin{array}{c}\text { Gövde } \\
\text { fleksiyonu }\end{array}$ & $\begin{array}{c}\text { Omuz } \\
\text { fleksiyonu }\end{array}$ & $\begin{array}{c}\text { Dirsek } \\
\text { fleksiyonu }\end{array}$ & RULA \\
\hline 1 & 41 & 38 & 23 & 80 & 5 \\
\hline 2 & 33 & 10 & 18 & 110 & 6 \\
\hline 3 & 46 & 39 & 30 & 57 & 6 \\
\hline 4 & 49 & 43 & 44 & 120 & 6 \\
\hline 5 & 44 & 33 & 20 & 79 & 4 \\
\hline 6 & 41 & 25 & 24 & 54 & 7 \\
\hline 7 & 49 & 28 & 94 & 110 & 6 \\
\hline 8 & 31 & 19 & 15 & 110 & 4 \\
\hline
\end{tabular}

görüntüsü olarak yapılmış II. çekimin sonucu ise Tablo 2'de gösterilmiştir. Katılımcıların, II. çekimdeki en kötü postürleri l. çekime oranla kıyaslandığında; 1 ve 5 numaralı katılımcıların postüral risk dereceleri daha düşük yani olumlu yönde olduğu, 2 ve 6 numaralı katılımcıların postüral risk dereceleri daha yüksek yani olumsuz yönde olduğu, diğer katılımcıların ise postüral risk derecelerinde herhangi bir değişim olmadığı sonucuna varılmıştır.

Grafiklerde çalışmaya katılan bireylerin görsel geri bildirim aldığı andaki postürleri ile 2 saniye sonraki postürleri arasındaki farklar, görüntülerine baktıkları her an için özetlenmiştir (Grafik 1,2,3,4,5). Bu veriler doğrultusunda, bireylerin görsel geri bildirime baktıkları her anda postürlerini değiştirdikleri sonucuna varılmıştır.

$1,2,4,5,6,7$ ve 9. vakalarda ekrandaki görüntülerine baktıktan sonra boyun fleksiyonunda bazı anlarda artma bazı anlarda azalma olduğu görülmüştür. Yalnızca birinci vakanın 3. bakışında herhangi bir değişim görülmemiştir. 3 ve 8 numaralı vakalarda ise boyun fleksiyonunda yalnızca azalma görülmüştür (Grafik 1). 


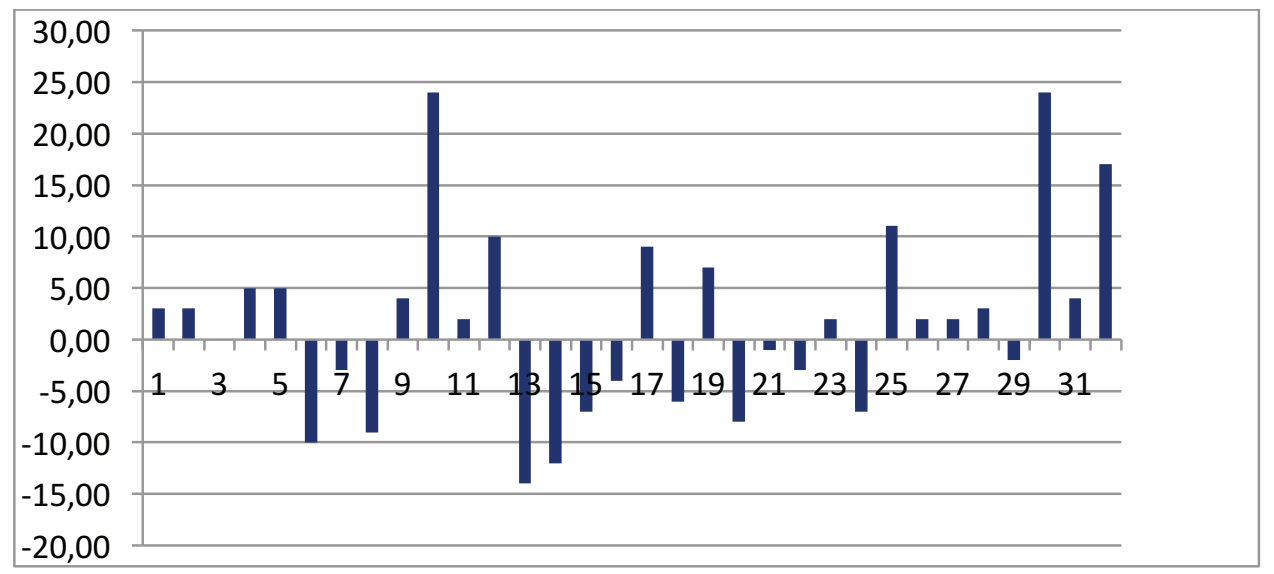

Grafik 1. Boyun fleksiyon açısı değişimleri (Değerler derece cinsinden verilmiştir)
1-4 değerleri $\rightarrow 1$. katılımcı
11-14 değerleri $\rightarrow$ 4. Katılımcı
5-9 değerleri $\rightarrow 2$. katılımcı
15-17 değerleri $\rightarrow 5$. katılımcı
10 değeri $\rightarrow 3$. katılımcı
18-21 değerleri $\rightarrow 6$. Katılımcı
22-25 değerleri $\rightarrow 7$. katılımcı
26-28 değerleri $\rightarrow$ 8. Katılımcı

29-32 değerleri 9. Katıımcı

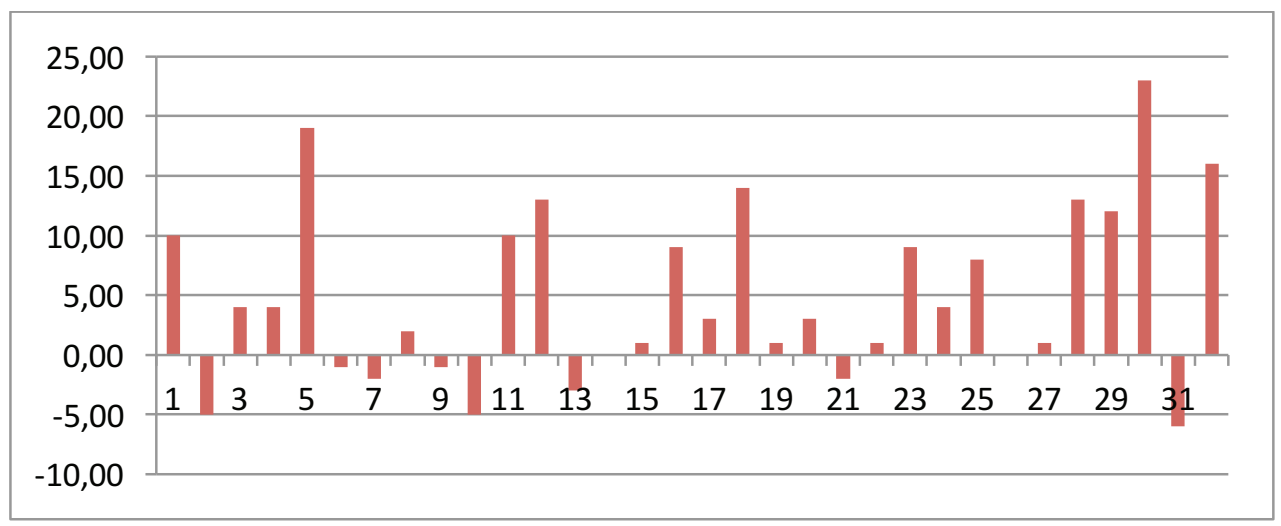

Grafik 2. Gövde fleksiyon açısı değişimleri (Değerler derece cinsinden verilmiştir)

1-4 değerleri $\rightarrow 1$. katılımcı

5-9 değerleri $\rightarrow 2$. katılımcı

10 değeri $\rightarrow 3$. katılımcı

22-25 değerleri $\rightarrow 7$. katılımcı

29-32 değerleri 9. Katılımcı
11-14 değerleri $\rightarrow 4$. Katılımcı

15-17 değerleri $\rightarrow 5$. katılımcı

18-21 değerleri $\rightarrow 6$. Katılımcı

26-28 değerleri $\rightarrow 8$. Katılımcı 


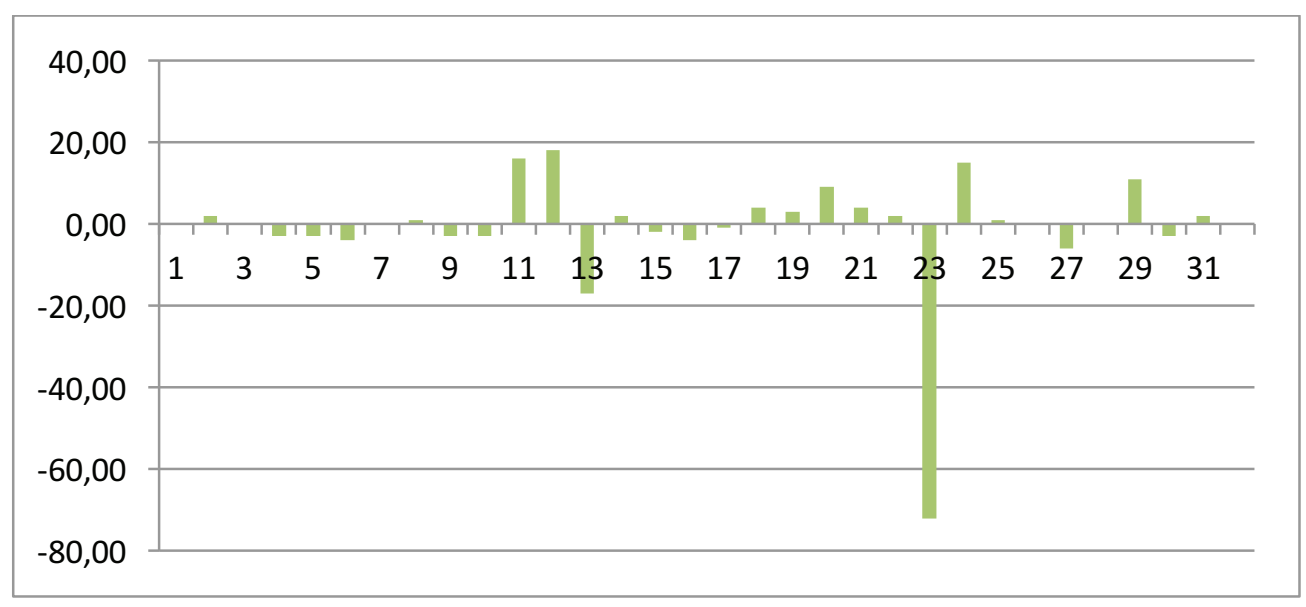

Grafik 3. Omuz fleksiyonaçısı değişimleri (Değerler derece cinsinden verilmiştir)

$$
\begin{aligned}
& \text { 1-4 değerleri } \rightarrow 1 \text {. katılımcı } \\
& \text { 5-9 değerleri } \rightarrow 2 \text {. katıımcı } \\
& 10 \text { değeri } \rightarrow 3 \text {. katılımcı }
\end{aligned}
$$$$
\text { 22-25 değerleri } \rightarrow 7 \text {. katılımcı }
$$$$
\text { 29-32 değerleri 9. Katılımcı }
$$

\author{
11-14 değerleri $\rightarrow 4$. Katılımcı \\ 15-17 değerleri $\rightarrow 5$. katılımcı \\ 18-21 değerleri $\rightarrow 6$. Katılımcı \\ 26-28 değerleri $\rightarrow 8$. Katılımcı
}

$1,2,4,6$ ve 9. vakalarda görüntülerine baktıktan sonra gövde fleksiyonunda hem artma hem azalma görülmüştür. 5,7 ve 8 . vakalarda gövde fleksiyonunda yalnızca azalma görülmüştür. 3 . vakada ise gövde fleksiyonunda yalnızca artma görülmüştür. 4. vakanın üçüncü bakışında ve 8. vakanın birinci bakışında gövde fleksiyonunda herhangi bir değiş̧im olmamıştır (Grafik 2).

$1,2,4,7$ ve 9. kişilerde omuz fleksiyonunda hem artma hem azalma olduğu bulunmuştur. 3, 5 ve 8 . kişilerde omuz fleksiyonunda yalnızca artma olurken 6. kişide yalnızca azalma görülmüştür. 1. ve 8. kişinin bir ve üçüncü bakışında, 2. kişinin üçüncü bakışında, 9. kişinin dördüncü bakışında omuz fleksiyonunda herhangi bir değişim olmamıştır (Grafik 3).

Dirsek fleksiyonunda $1,2,4,5,6,7,8$ ve 9. kişilerde hem azalma hem artma görülürken olduğu bulunmuştur. 3. kişide dirsek fleksiyonunda yalnızca azalma görülmüştür. 5. ve 7. kişilerde üçüncü bakışlarında, 6. ve 9. kişilerde dördüncü bakışlarında dirsek fleksiyonunda herhangi bir değişim olmamıştır (Grafik 4).

RULA değerlerinde 1. kişinin tüm bakışlarında, 2. kişinin üçüncü, dördüncü ve beşinci bakış- larında, 5. kişinin ikinci bakışında, 6. kişinin birinci ve ikinci bakışında, 7. kişinin birinci bakışında, 8 . kişinin ikinci ve üçüncü bakışında, 9. kişinin üçüncü bakışında herhangi bir değişim olmamıştır. Diğer bakışlarda hem azalma hem de artma görülmüştür (Grafik 5).

\section{TARTIȘMA}

Çalışmada, görsel geribildirimin postüre olan etkisine bakılabilmesi için, kişisel olarak postüral değişimler değerlendirilmiştir. Karşılaştırmalar bireysel değişimler üzerinden yapıImıştır. Çalışmanın sonucunda kişilerin ön kameraya baktıktan sonra boyun fleksiyonu, gövde fleksiyonu, omuz fleksiyonu, dirsek fleksiyonu ve RULA değerlerinde değişim olduğu, postürün değiştiği bulunmuştur. Olumlu değişimin en fazla olduğu değer gövde fleksiyonunda görülürken, olumlu değişimin en az olduğu değer RULA değerlerinde görülmüştür. Görsel geri bildirim ile postür arasında bir ilişki olduğu ve hazırlanan sanal ortamda görsel geri bildirimin postüre etki ettiği sonucuna varılmıştır.

En kötü postürlere bakıldığı zaman 1. çekim ve 2. çekimdeki karşılaştırmalara göre 5 bireyde herhangi bir değişim gözlenmezken, 4 bireyde 


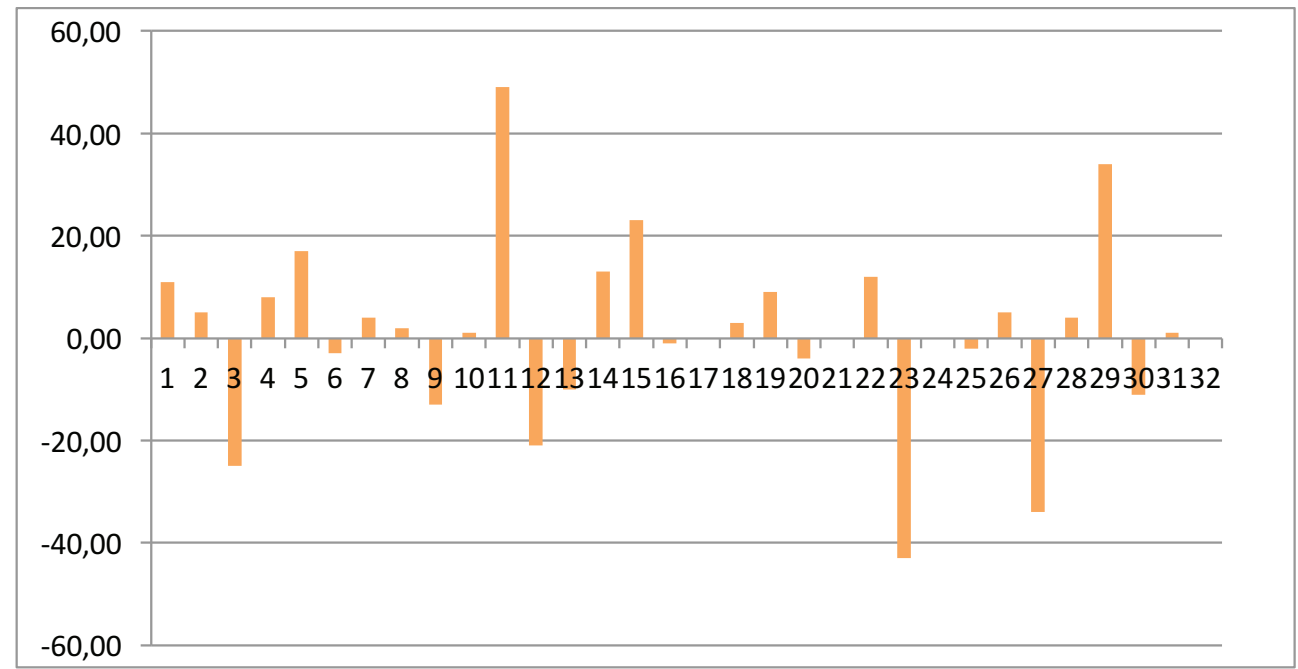

Grafik 4. Dirsek fleksiyon açısı değişimleri (Değerler derece cinsinden verilmiştir)

1-4 değerleri $\rightarrow 1$. katılımcı

5-9 değerleri $\rightarrow 2$. katılımcı

10 değeri $\rightarrow 3$. katılımcı

22-25 değerleri $\rightarrow 7$. katılımcı

29-32 değerleri 9. Katılımcı
11-14 değerleri $\rightarrow 4$. Katılımcı

15-17 değerleri $\rightarrow 5$. katılımcı

18-21 değerleri $\rightarrow 6$. Katılımcı

26-28 değerleri $\rightarrow 8$. Katılımcı

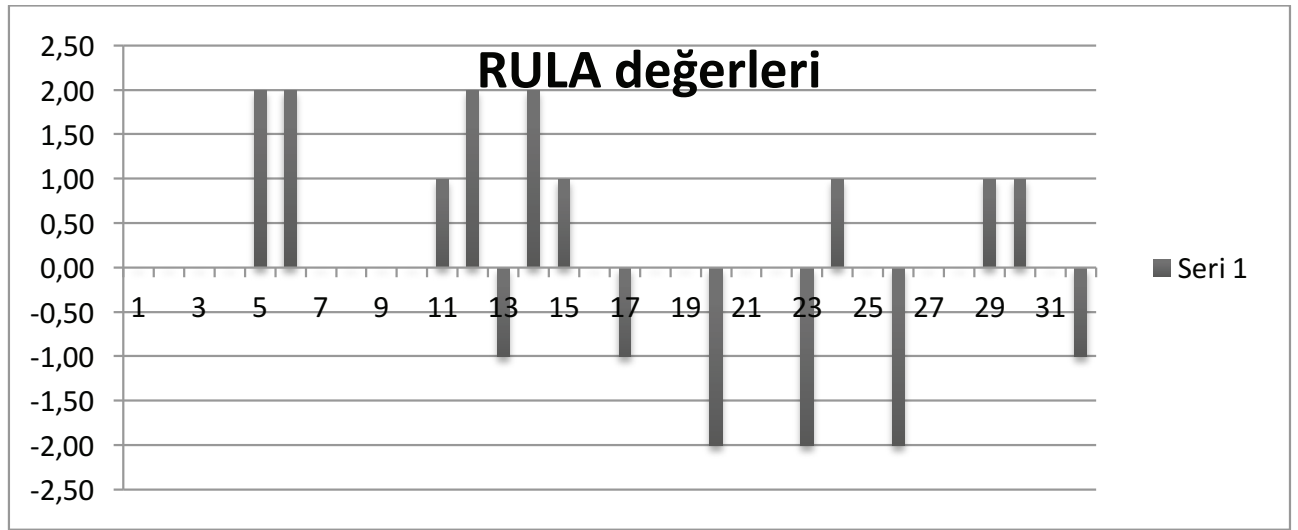

Grafik 5. RULA değerleri değişimleri

1-4 değerleri $\rightarrow 1$. katılımcı

5-9 değerleri $\rightarrow$ 2. katılımcı

10 değeri $\rightarrow 3$. katılımcı

22-25 değerleri $\rightarrow 7$. katılımcı

29-32 değerleri 9. Katılımcı
11-14 değerleri $\rightarrow 4$. Katılımcı

15-17 değerleri $\rightarrow 5$. katılımcı

18-21 değerleri $\rightarrow 6$. Katılımcı

26-28 değerleri $\rightarrow$ 8. Katılımcı 
olumlu yönde 1 bireyde olumsuz yönde değişim gösterilmiştir. Kişilerin çekimler sırasında sergiledikleri en kötü postürler görsel geri bildirim sağlanan bir ortamda görüntüsüne bakmasa dahi postürünü doğru postüre daha yakın pozisyonda tuttuğu çekimlerin karşılaştırılması sonucunda bulunmuştur.

Postürün düzeltilmesi için McCann ve SulzerAzaroff (1996) ‘ın yaptığı bir çalışmada postürün gelişimi için görsel geri bildirimi kullandığında postürde olumlu değişim olduğunu belirtmiştir (McCann, Sulzer-Azaroff, 1996).

Sigurdsson ve Austin (2008) ise 8 kişi ile bilgisayar çalışanlarında postürü geliştirebilmek için gerçek zamanlı görsel geri bildirimi kullanmıştır. Çalışmasında, değerlendirme öncesi güvenli ve riskli postürler hakkında katılımcılara eğitim verilmiş ve doğru postür hakkında farkındalık kazanmalarını sağlamıştır. Çalışmada postürün gelişiminde değerlendirme öncesi verilen eğitimin yardımıyla olumlu gelişmeler kaydettiklerini ifade etmişlerdir (Sigurdsson, Austin, 2008). Bizim çaIışmamızda postür hakkında daha önce herhangi bir eğitim alarak farkındalığı sağlanmamış bireyler seçilmiştir. Bireyler doğru postür hakkında eğitimleri olmamasına rağmen postürlerini olumlu yönde değiştirmişlerdir. Değerlendirme öncesi eğitim alan bireylerin çalışmaya dahil edildiği koşulda postürde olumlu değişim daha yüksek düzeyde olacağı düşünülmektedir.

Çalışmada postürde olumlu değişimin en yüksek düzeyde olduğu alan gövde fleksiyonu olmuştur. Bireyler klavyede yazı yazarken, yazının doğruluğunu kontrol edebilmek amacıyla bilgisayar ekranına bakmaları gerekmiştir. Klavyede yazı yazma sırasında gövdelerini istemsiz olarak yakınlaştırıp yazmışlar ve ekrana baktıklarında hem Word dosyasını hem de kendi görüntülerini görmüşlerdir. Gördükten sonra geriye doğru çekilme davranışını yaptıkları için gövde fleksiyonu ekrana baktıktan sonra azalma eğilimi göstermiştir. Gövde fleksiyonunun azalması olumlu bir hareket olduğu için, postürde en yüksek olumlu değişim gövde fleksiyonunda görülmüştür.

Çalışmada postüral değişiklikleri anlayabilmek için RULA kullanılmıştır. RULA risk faktörlerini değerlendirmek üzere oluşturulmuş, belli değer aralıklarından oluşan bir sistemdir. RULA risk faktörü azaldıkça doğru postür oluşumu artmaktadır
(Dockrell ve ark., 2012). RULA değerleri genel anlamda ErgoFellow programı ile tespit ettiğimiz boyun fleksiyonu, gövde fleksiyonu, omuz fleksiyonu ve dirsek fleksiyonu derecelerinde küçük çaplı değişimleri yansıtmakta yetersiz kalmıştır. Çalışmamızda, kişilerin postürlerinde değişim olduğu halde, çoğu zaman RULA için farklı bir değeri ifade etmemiştir. Bu yüzden postürdeki olumlu değişim oranlarına baktığımızda en az değişim RULA değerlerinde görülmüştür.

Katılımcı sayısının 10 kişi ile sınırlı kalması genele uyarlanması açısından yetersizdir. Çalışmada bireylere doğru postür hakkında eğitim verilmemesi ve ön kameranın ekranda bulunma sebebinin açıklanmaması çalışmanın limitasyonlarıdır. Aynı zamanda bireyler bilimsel bir çalışmanın sonucunu etkilemekten çekindikleri için doğal hallerini sergileyememişlerdir. Bu durum çalışmanın diğer bir limitasyonu olmuştur.

Çalışmamızda görsel geri bildirimin, yoğun olarak görülen postüral problemlerin oluşumuna engel olmak için, kullanılabilecek yöntemlerden birisi olduğu açığa çıkmıştır. Bilgisayarın hayatın her aşamasında olması, sağlığımıza uygun hale getirmeyi zorunlu kılmıştır. Bunun için bireye özel bilgisayar ekipmanı yapılması dışında, yeni yollar da keşfedilmelidir. Ön kameranın postür üzerinde olumlu etki ettiğini ve bilgisayar kullanımı sırasında ekranın kenarından elde edebilecekleri görsel geri bildirimin dikkate alınmasının, bireylerde postüral problemleri azaltacağı düşünülmektedir. Bu değerlerin doğru postür eğitiminin verilmesi ile postüral gelişimin daha fazla olacağı düşünülmektedir.

\section{Kaynaklar}

Açık, E., Kayıhan, H., \& Aran, O. T. (2014). IIlköğretim okullarında okul mobilyasının antropometrik uygunluğunun değerlendirilmesi-pilot çalışma. Ergoterapi ve Rehabilitasyon Dergisi, 2(3), 131-140.

Altschuler, E. L., \& Hu, J. (2008). Mirror therapy in a patient with a fractured wrist and noactive wrist extension. Scand J Plast Reconstr Surg Hand Surg, 42(2), 110111.

Deros, B. M., Ali, M. H., Mohamad, D., \& Daruis, D. D. I. (2016). Ergonomic risk assessment on oil palm industry workers. Iran J Public Health, 45(1), 44-51. 
Dockrell, S., O'Grady, E., Bennett, K., Mullarkey, C., McConnell, R., Ruddy, R., \& Flannery, C. (2012). An investigation of reliability of Rapid Upper Limb Asessment (RULA) as a method of assessment of children's computing postüre. Appl Ergon, 43(3), 632-636.

Esen, H., \& Fığlalı, N. (2013). Çalışma duruşu analiz yöntemleri ve çalışma duruşunun kas-iskelet sistemi rahatsızlıklarına etkileri. Sakarya Üniversitesi Fen Bilimleri Enstitüsü Dergisi, 17(1).

Kelly, J. W., Riecke, B., Loomis, J. M., \& Beall, A. C. (2008). Visual control of posture in realand virtual environments. Percept Psychophys, 70(1), 158-165.

Levanon, Y., Lerman, Y., Gefen, A., \& Ratzon, N. Z. (2014). Validity of the modified RULA for computer workers and reliability of one observation compared to six. Ergonomics, 57(12), 1856-1863.

McCabe, C. (2011). Mirror visual feedback therapy. A practical approach. J Hand Ther, 24(2), 170-179.

McCann, K. B., \& Sulzer-Azaroff, B. (1996). Cumulative trauma disorders: Behavioral injury prevention at work. J Appl Behav Sci, 32(3), 277-291.

Sato, K., Fukumori, S., Matsusaki, T., Maruo, T., Ishikawa, S., Nishie, H., \& Nakatsuka, H. (2010). Nonimmersive virtual reality mirror visual feedback therapy and its application for the treatment of complex regional pain syndrome: an open-label pilot study. Pain Med, 11(4), 622-629.

Selles, R. W., Schreuders, T. A., \& Stam, H. J. (2008). Mirror therapy in patients with causalgia (complex regional pain syndrome type II) following peripheral nerve injury: two cases. J Rehabil Med, 40(4), 312-314.

Sigurdsson, S.O., \& Austin, J. (2008). Using real-time visual feed back to improve posture at computer workstations. J Appl Behav Anal, 41(3), 365-375.

Yavuzer. G., Selles, R., Sezer, N., Sütbeyaz, S., Bussmann, J. B., Köseoğlu, F., \& Stam, H. J. (2008). Mirror therapy improves hand function in subacute stroke: a randomized controlled trial. Arch Phys Med Rehabil, 89(3), 393-398. 
